\title{
Correction to: Fracture resistance and marginal gap formation of post-core restorations: influence of different fiber-reinforced composites
}

\author{
Márk Fráter $^{1} \cdot$ Lippo Lassila $^{2} \cdot$ Gábor Braunitzer $^{3} \cdot$ Pekka K. Vallittu $^{2,4} \cdot$ Sufyan Garoushi $^{2}$ \\ Published online: 23 January 2021 \\ (C) Springer-Verlag GmbH Germany, part of Springer Nature 2021
}

\section{Correction to: Clinical Oral Investigations} https://doi.org/10.1007/s00784-019-02902-3

The authors regret that the tested groups in Fig. 4 were not in the right order and this mistake is only present in Fig. 4 (micohardness results). This does not influence the discussion or the conclusion of the study.

Please find below corrected Fig. 4 in order to aid the interpretation of microhardness results.

In results part, page 270 , last paragraph: group 4 should be group 5. In discussion part, page 273 , 2nd line on the right column: group 5 should be group 4 .

The authors would like to apologize for any inconvenience caused.

The online version of the original article can be found at https://doi.org/ 10.1007/s00784-019-02902-3

Sufyan Garoushi sufgar@utu.fi

1 Department of Operative and Esthetic Dentistry, Faculty of Dentistry, University of Szeged, Szeged, Hungary

2 Department of Biomaterials Science and Turku Clinical Biomaterials Center - TCBC Institute of Dentistry, University of Turku, Itäinen Pitkäkatu 4 B, FI-20520 Turku, Finland

3 dicomLAB Dental Ltd., Szeged, Hungary

4 City of Turku Welfare Division, Oral Health Care, Turku, Finland 
Fig. 4 Microhardness (VH) mean values for resin composites at the top (coronal) and bottom (apical) parts of the root canal. Arrows above the columns indicate $\mathrm{VH}$ of these groups dropped below $80 \%$ of the coronal part values.

Vertical lines represent standard deviation

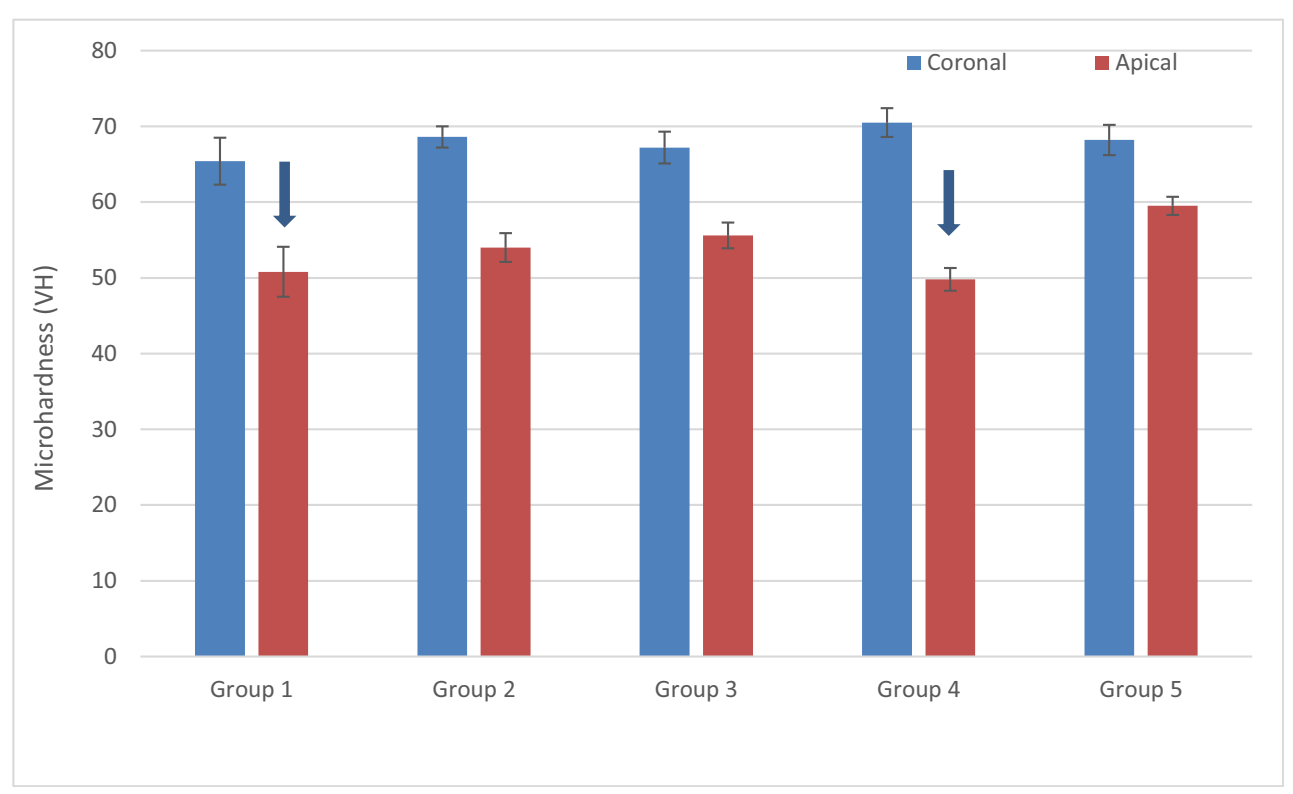

Publisher's note Springer Nature remains neutral with regard to jurisdictional claims in published maps and institutional affiliations. 